\title{
STUDI FONDASI TIANG BOR UNTUK JEMBATAN DI LAUT
}

\author{
Arvin $^{1}$ dan Aniek Prihatiningsih ${ }^{2}$ \\ ${ }^{1}$ Program Studi Sarjana Teknik Sipil, Universitas Tarumanagara. Jl. Letjen S. Parman No.1 Jakarta \\ arvin.325170002@stu.untar.ac.id \\ ${ }^{2}$ Program Studi Sarjana Teknik Sipil, Universitas Tarumanagara Jl. Letjen S. Parman No.1 Jakarta \\ aniekp@ft.untar.ac.id
}

Masuk: 18-01-2021, revisi: 01-02-2021, diterima untuk diterbitkan: 11-02-2021

\begin{abstract}
Structurally, the bridge is separated into the upperstructure, and substructure such as foundation. According to its function, the foundation of the bridge supports and transmits the load from the superstructure to a strong and stable layer of soil. The construction of a bridge at sea has a high level of difficulty and risk. There are forces that influence the foundation at sea. The greater the loads that are held by the foundation, the greater the bearing capacity required for the foundation. The foundation used the bored pile casing method. The concept of a bored pile foundation casing method itself uses a steel casing pipe that is installed to a specified depth. This method is used when the borehole is very prone to landslides, so it is very suitable to be applied to soil which is sand below the groundwater level or at sea. In this paper, we will discuss the bearing capacity of the bored pile foundation and the loads that affect the bearing capacity of the foundation. Bearing capacity includes axial and lateral bearing capacity. So the results of this study will show how much effective bearing capacity must be considered when creating a foundation for bridges at sea.
\end{abstract}

Keywords: foundation at sea; forces that work at sea; bored pile; casing method; bearing capacity; loads at sea.

\begin{abstract}
ABSTRAK
Secara struktural jembatan dipisahkan menjadi struktur atas, dan struktur bagian bawah seperti fondasi. Sesuai fungsinya, fondasi jembatan menopang dan meneruskan beban dari bangunan atas jembatan ke lapisan tanah yang kuat dan stabil/solid. Pembangunan jembatan panjang di tengah laut memiliki tingkat kesulitan dan resiko tinggi. Terdapat gaya-gaya yang mempengaruhi fondasi yang dibuat di laut. Semakin besar beban-beban yang ditahan fondasi maka semakin besar pula daya dukung yang dibutuhkan fondasi. Fondasi yang dipakai adalah fondasi tiang bor dengan metode casing. Konsep dari fondasi tiang bor metode casing sendiri menggunakan pipa selubung baja (casing) yang diinstall sampai kedalaman yang ditentukan. Metode ini digunakan bila lubang bor sangat mudah longsor, sehingga sangat cocok untuk diaplikasikan pada tanah yang merupakan pasir di bawah muka air tanah atau di laut. Pada penulisan ini akan dibahas mengenai daya dukung fondasi tiang bor dan beban-beban yang mempengaruhi daya dukung fondasi tersebut. Daya dukung mencakup daya dukung aksial dan lateral. Sehingga hasil studi ini akan menunjukan seberapa besar daya dukung efektif yang harus dipertimbangkan pada saat ingin membuat fondasi untuk jembatan di laut.
\end{abstract}

Kata kunci: fondasi di laut; gaya-gaya yang bekerja di laut; tiang bor metode casing; daya dukung; beban-beban di laut.

\section{PENDAHULUAN}

Sebagai salah satu prasarana transportasi, jembatan menjadi akses bagi masyarakat untuk memenuhi kebutuhan barang dan jasa sehari-hari. Untuk meningkatkan pertumbuhan ekonomi, dan pembangunan konstruksi di daerah tersebut. Jembatan adalah sutau konstruksi yang berfungsi untuk meneruskan jalan melalui suatu rintangan misalnya laut, selat, sungai, jurang dan sebagainya.

Seiring dengan perkembangan zaman, jembatan tidak hanya menghubungkan dua titik bersebrangan yang berbeda, namun sudah sapat menghubungkan antar pulau hingga negara. Kondisi lapangan yang kurang mendukung serta akses menuju jembatan yang sulit dijangkau menjadi kendala tambahan dalam pembangunan struktur jembatan yang melintasi permukaan laut.

Berdasarkan bagiannya, jembatan terdiri dari struktur atas (superstructures) yang meneima beban langsung meliputi beban mati dan beban hidup, dan struktur bawah (substructure) yang memikul seluruh beban struktur atas 
dan beban lain, yang ditimbulkan oleh tekanan tanah, aliran air, dan hanyutan, gesekan serta tumbukan pada tumpuan dan diteruskan ke fondasi (Almuhitsyah, 2012).

Fondasi yang merupakan bagian dari substructures memiliki fungsi meneruskan seluruh beban jembatan ke tanah dasar, dan menopang jembatan tersebut. Terdapat perbedaan dalam perencanaan fondasi di darat dan di laut seperti jenis tanah, besarnya beban yang didukung, kondisi daerah sekitar, akses ke lapangan yang sulit untuk dijangkau. Umumnya fondasi yang digunakan pada struktur jembatan adalah fondasi dalam (Almuhitsyah, 2012).

Dalam penelitian ini, penulis akan meneliti faktor-faktor apa saja yang mempengaruhi fondasi untuk jembatan di laut. Dalam penulisan ini jenis fondasi yang digunakan adalah fondasi tiang bor dengan metode casing. Selain itu penulis akan menghitung daya dukung efektif fondasi tiang bor setelah direduksi oleh beban-beban yang mempengaruhinya..

Batasan-batasan masalah pada penelitian ini adalah sebagai berikut:

1. Parameter tanah yang digunakan berdasarkan hasil uji laboratorium dan uji lapangan,

2. Konstruksi bagian superstructures dan substructures jembatan diabakan,

3. Pembahasan tidak mencakup pembesian fondasi,

4. Penurunan fondasi diabaikan,

5. Beban angin dan beban gempa tidak diperhitungkan,

6. Daya dukung aksial tarik tidak diperhitungkan

7. Perhitungan tidak mencakup daya dukung kelompok tiang.

Berdasarkan uraian yang sudah disebutkan sebelumnya, masalah yang harus diselesaikan yaitu:

1. Jenis-jenis fondasi untuk jembatan di laut,

2. Permasalahan yang terjadi pada saat pembuatan fondasi di laut,

3. Metode pelaksanaan fondasi tiang bor di laut,

4. Beban-beban yang mempengaruhi fondasi di laut,

5. Daya dukung aksial dan lateral fondasi tiang bor,

6. Daya dukung efektif fondasi tiang bor.

Berdasarkan rumusan masalah yang ada, maka tujuan penelitian ini adalah sebagai berikut:

1. Mengetahui jenis-jenis fondasi yang digunakan untuk jembatan di laut,

2. Mengetahui permasalahan yang terjadi pada saat pembuatan fondasi di laut,

3. Mengetahui metode pelaksanaan fondasi tiang bor di laut,

4. Mengetahui beban-beban yang mempengaruhi fondasi di laut,

5. Mengetahui daya dukung aksial dan lateral fondasi tiang bor,

6. Mengetahui daya dukung efektif fondasi tiang bor.

\section{Jenis-jenis fondasi yang diguankan untuk jembatan di laut}

Dalam pembangunan jembatan di laut terdapat beberapa macam fondasi yang dapat digunakan. Pemilihan jenis fondasi ditentukan oleh kondisi tanah dan desain struktur atas jembatan. Berikut beberapa jenis fondasi yang dapat digunakan (Almuhitsyah):

1. Fondasi sumuran (Caisson),

2. Fondasi tiang pancang dan tiang bor,

3. Fondasi jacket atau tripod.

\section{Faktor-faktor yang mempengatuhi fondasi di laut}

Terdapat kendala tambahan yang terjadi pada fondasi jembatan yang dibuat di laut. Berikut beberapa faktor yang mempengaruhinya:

1. Korosi

2. Scouring (Gerusan)

3. Beban tumbukan kapal (Berthing Forces)

4. Beban arus

5. Beban Debris

6. Beban jembatan

\section{Fondasi tiang bor}

Fondasi tiang bor (bored pile) adalah fondasi tiang yang dilakukan pengeboran tanah pada tahap awal pengerjaannya, setelah itu dimasukkan tulangan dan dicor beton. Tiang bor biasa digunakan pada tanah yang stabil 
dan kaku, sehingga dapat membentuk lubang yang stabil dengan alat bor. Jika tanah mengandung air, diperlukan pipa besi (casing) untuk menahan dinding lubang agar tidak longsor. Terdapat tiga metode dalam pelaksanaan fondasi tiang bor (Chomaedi):

1. Metode kering,

2. Metode basah (Slurry),

3. Metode casing.

\section{Fondasi tiang bor metode casing}

Metode casing digunakan pada kondisi dimana lubang bor sangat mudah longsor, misalnya tanah di lokasi adalah pasir bersih di bawah muka air tanah seperti di laut. Untuk menahan agar lubang tidak longsor digunakan pipa selubung baja (casing). Pemasangan casing ke dalam lubang bor dilakukan dengan cara memancang, menggetarkan atau menekan pipa baja sampai kedalaman yang ditentukan. Sebelum sampai menembus muka air tanah, pipa baja (casing) demasukkan, tanah di dalam pipa baja dikeluarkan saat penggalian atau setelah pipa baja sudah sampai kedalaman yang diinginkan (Chomaedi, 2009). Langkah-langkah pelaksanaan metode casing dapat dilihat pada gambar 1 .

Larutan bentonite (slurry) digunakan untuk menahan tekanan dari air atau tanah yang mudah longsor. Setelah pipa selubung sampai pada kedalaman yang diinginkan, lubang bor dibersihkan dan tulangan yang sudah dirangkai dimasukkan ke dalam casing. Selanjutnya adukan beton dimasukkan ke dalam lubang (bila pembuatan lubang menggunakan larutan, maka untuk pengecoran digunakan pipa tremie). Casing dapat ditarik ke atas setelah selesai, dan terkadang casing ditinggalkan di tempat (Chomaedi, 2009).

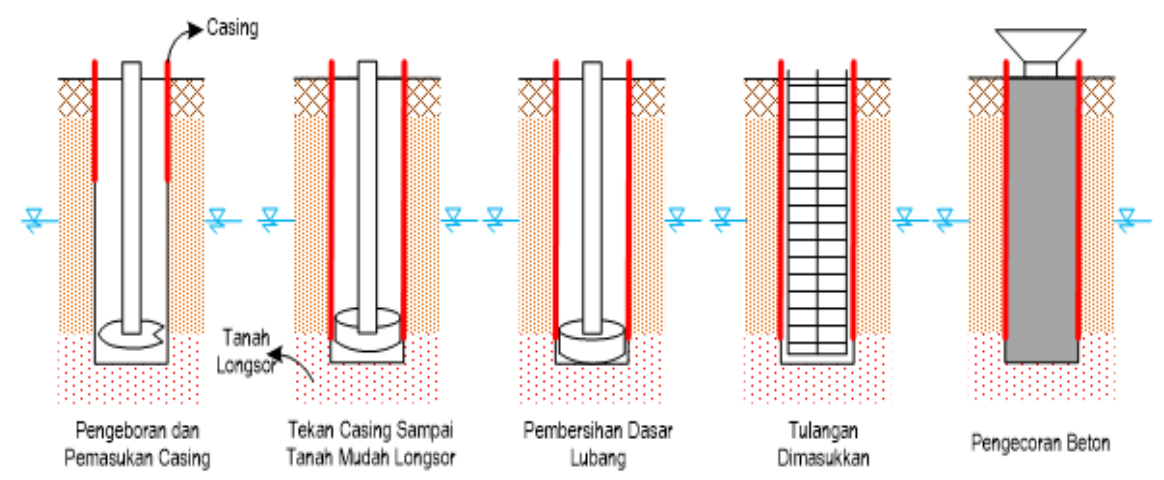

Gambar 1. Langkah-lankah pelaksanaan tiang bor metode casing (Chomaedi, 2009)

\section{Daya dukung ujung tiang}

Daya dukung ujung tiang pada tanah lempung menurut Skempton (Bowles, 1996), dapat dihitung menggunakan persamaan.

$$
\mathrm{Q}_{\mathrm{p}}=\mathrm{A}_{\mathrm{p}} 9 \mathrm{C}_{\mathrm{u}}
$$

dengan $\mathrm{Q}_{\mathrm{p}}=$ tahanan ujung tiang, $\mathrm{A}_{\mathrm{p}}=$ luas penampang tiang, $\mathrm{C}_{\mathrm{u}}=$ kohei taksalur untuk tanah di bawah ujung tiang.

\section{Daya dukung tiang gesekan kulit}

Daya dukung tiang gesekan kulit atau tahanan kulit (Das, 1995), pada tanah lempung menurut metode $\alpha$ Tomlinson (Bowles, 1996), dapat dihitung menggunakan persamaan.

$$
\mathrm{Q}_{\mathrm{s}}=\Sigma \mathrm{fp} \Delta \mathrm{L}=\Sigma \alpha \mathrm{c}_{\mathrm{u}} \mathrm{p} \Delta \mathrm{L}
$$

Dengan,

$$
f=\alpha \mathrm{c}_{\mathrm{u}}
$$

dengan $\mathrm{Q}_{\mathrm{s}}=$ tahanan gesek selimut tiang, $\mathrm{p}=$ keliling tiang, $\Delta \mathrm{L}=$ panjang tiang, $\mathrm{f}=$ gesekan selimut, $\alpha=$ faktor adhesi empiris, dapat dilihat pada gambar $2, \mathrm{c}_{\mathrm{u}}=$ kuat geser tanah undrained. 


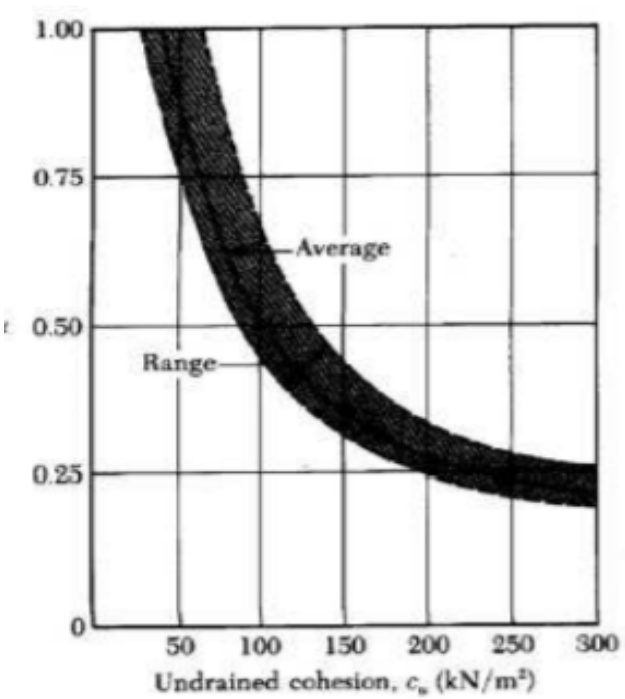

Gambar 2. Variasi $\alpha$ dengan kohesi taksalur, $\mathrm{c}_{\mathrm{u}}$ (Das, 1990)

\section{Daya dukung tiang}

Daya dukung tiang bor (Das, 1995), dapat dihitung menggunakan persamaan.

$$
\mathrm{Q}_{\mathrm{u}}=\mathrm{Q}_{\mathrm{p}}+\mathrm{Q}_{\mathrm{s}}
$$

dengan $\mathrm{Q}_{\mathrm{u}}=$ daya dukung ultimit tiang, $\mathrm{Q}_{\mathrm{p}}=$ tahanan ujung tiang, $\mathrm{Q}_{\mathrm{s}}=$ tahanan gesek selimut tiang.

\section{Daya dukung ijin tiang}

Dengan diperolehnya daya dukung batas, maka daya dukung ijin dapat diperoleh dengan memakaikan suatu faktor keamanan, sehingga beban ijin total untuk masing-masing tiang dapat dihitung dengan persamaan.

$$
\mathrm{Q}_{\mathrm{all}}=\frac{\mathrm{Q}_{\mathrm{u}}}{\mathrm{FS}}
$$

Dengan $\mathrm{Q}_{\mathrm{all}}=$ daya dukung ijin masing-masing tiang, $\mathrm{Q}_{\mathrm{u}}=$ daya dukung ultimit tiang, $\mathrm{FS}$ = faktor keamanan.

\section{Daya dukung lateral tiang}

Metode Broms (Hardiyatmo, 2008) dapat digunakan untuk menghitung tahanan maksimum akibat gaya lateral baik rigid piles maupun long piles yang berada pada lapisan tanah homogen dan murni berupa tanah kohesif atau granuler. Daya dukung lateral tiang dalam tanah kohesif dapat dihitung menggunakan persamaan.

$$
\begin{gathered}
H_{u}=\frac{2 M_{y}}{1.5 D+\frac{f}{2}} \\
f=\frac{H u}{9 \text { Cu D }} \\
\mathrm{kp}=\left(\tan \left(45+\frac{\Phi}{2}\right)\right)^{2} \\
\text { Mmax }=\gamma \mathrm{L}^{3} \mathrm{D} \mathrm{kp} \\
\text { My }=\frac{1}{8} A \gamma \mathrm{D}^{2} \mathrm{~L}^{2} \\
\text { Yo }=\frac{\mathrm{Hu} \mathrm{B}}{\mathrm{kh} \mathrm{D}} \\
\mathrm{B}=\left(\frac{\mathrm{kh} \mathrm{D}}{4 \mathrm{Ep} \mathrm{Ip}}\right)^{\frac{1}{4}}
\end{gathered}
$$


dengan $\mathrm{Hu}=$ daya dukug lateral tiang, $\mathrm{My}=$ momen maksimum yang dapat ditahan tiang, $\mathrm{d}=$ diameter tiang, $\mathrm{f}=$ jarak kedalam titik dimana gaya geser sama dengan nol, $\mathrm{Kp}=$ koefisien tanah pasif, dan $\gamma=$ berat volume tanah.

\section{Korosi}

Korosi termasuk salah satu masalah yang sering dihadapi paada struktur baja yang dibangun di kawasan laut. Air laut yang banyak mengandung garam merupakan penyebab korosi yang utama. Sistem proteksi korosi pada pipa pancang dapat dilakukan dengan memakai coating system. Coating system adalah Suatu proses pelapisan yang diterapkan pada pipa pancang dengan tujuan untuk meningkatkan ketahanan permukaan terhadap korosi. Beberapa jenis coating yang digunakan adalah coal tar epoxy coating dan glass flake epoxy coating.

\section{Scouring}

Gerusan (scouring) adalah proses erosi dan deposisi yang terjadi karena perubahan aliran di sungai. Scouring effect sering menjadi salah satu biang masalah pada tiang bangunan offshore, dikarenakan komponen tiang yang bertemu dengan tanah akan terlihat seperti memiliki lubang. Hal ini yang dapat menyebabkan kegagalan sebuah pelabuhan yang disebabkan oleh penurunan daya dukung tanah akibat tanah yang hilang atau terangkat karena gerusan oleh air disekitar tiang. Perhitungan kedalaman gerusan pada struktur tiang menurut FEMA P-550 (John, 2019), dapat dihitung dengan metode persamaan.

$$
\mathrm{S}_{\max }=2 a
$$

dengan $\mathrm{S}_{\max }=$ kedalaman scouring maksimum, dan $a$ = diameter fondasi lingkaran atau diagonal maksimum fondasi segiempat.

\section{Beban tumbukan kapal (berthing forces)}

Perhitungan besarnya energi benturan akibat kapal menurut OCDI (Rindianto, 2018), dapat dihitung dengan metode persamaan.

$$
E=\frac{1}{2} \mathrm{M}_{\mathrm{s}} V^{2} \mathrm{C}_{\mathrm{m}} \mathrm{C}_{\mathrm{e}} \mathrm{C}_{\mathrm{s}} \mathrm{C}_{\mathrm{c}}
$$

dengan $\mathrm{E}$ = energi tumbukan kapal, $\mathrm{M}_{\mathrm{s}}=$ berat kapal, $\mathrm{V}=$ kecepatan kapal saat merapat, $\mathrm{C}_{\mathrm{m}}=$ koefisien massa, $\mathrm{C}_{\mathrm{e}}$ $=$ koefisien eksentrisitas, $\mathrm{C}_{\mathrm{s}}=$ koefisien kekerasan, dan $\mathrm{C}_{\mathrm{C}}=$ koefisien dari tambatan.

Dengan data kapal dapat dilihat pada tabel 1 (Rindianto, 2018),

Tabel 1. Tabel dimensi kapal (Rindianto, 2018)

\begin{tabular}{ccccccc}
\hline $\begin{array}{c}\text { Tipe } \\
\text { Kapal }\end{array}$ & $\begin{array}{c}\text { Bobot Kapal } \\
\text { (ton) }\end{array}$ & $\begin{array}{c}\text { Displacement } \\
\text { (ton) }\end{array}$ & $\begin{array}{c}\text { Loa } \\
(\mathrm{m})\end{array}$ & $\begin{array}{c}\text { Lebar (B) } \\
(\mathrm{m})\end{array}$ & $\begin{array}{c}\text { Tinggi (D) } \\
(\mathrm{m})\end{array}$ & $\begin{array}{c}\text { Draft } \\
(\mathrm{m})\end{array}$ \\
\hline Kapal & 1000 & 1333 & 61 & 8,9 & 4,5 & 4,2 \\
Tanker & 5000 & 6667 & 103 & 16 & 6,5 & 6,5 \\
(Oil & 10000 & 13333 & 140 & 17,2 & 7,9 & 7,9 \\
Carrier) & 15000 & 20000 & 163 & 20 & 11,2 & 8,8 \\
& 20000 & 26667 & 174 & 23,7 & 12.3 & 9,5 \\
\hline
\end{tabular}

\section{Beban arus}

Perhitungan beban arus terhadap tiang menurut ASCE 7-05 (John, 2019), dapat dihitung dengan metode persamaan.

$$
\mathrm{F}_{\mathrm{brkp}}=\frac{1}{2} C D \gamma D \mathrm{H}_{\mathrm{b}}^{2}
$$

dengan $\mathrm{F}_{\text {brkp }}=$ beban arus, $\mathrm{CD}=$ koefisien drag untuk ombak pecah, $\gamma=$ berat jenis air, $\mathrm{D}=$ diameter tiang, dan $\mathrm{H}_{\mathrm{b}}$ $=$ ketinggian ombak pecah.

\section{Beban debris}

Beban debris berupa objek atau sampah terapung yang terbawa oleh aliran air sehingga mengenai bangunan. Perhitungan beban debris terhadap tiang menurut ASCE 7-05 (John, 2019), dapat dihitung dengan metode persamaan.

$$
\mathrm{F}_{\mathrm{i}}=\left(\pi W \mathrm{~V}_{\mathrm{b}} \mathrm{C}_{\mathrm{I}} \mathrm{C}_{\mathrm{O}} \mathrm{C}_{\mathrm{D}} \mathrm{C}_{\mathrm{B}} \mathrm{R}_{\max }\right) /(2 g \Delta t)
$$


dengan $\mathrm{F}_{\mathrm{i}}=$ beban debris, $\mathrm{W}=$ berat debris, $\mathrm{V}_{\mathrm{b}}=$ kecepatan objek, $\mathrm{C}_{\mathrm{I}}=$ importance coefficient, $\mathrm{C}_{\mathrm{O}}=$ orientation coefficient, $\mathrm{C}_{\mathrm{D}}=$ depth coefficient, $\mathrm{C}_{\mathrm{B}}=$ blockage coefficient, $\mathrm{R}_{\max }=$ respon maksimum beban impulsif, $\mathrm{g}=$ gravitasi, dan $\Delta t=$ durasi dari impact.

\section{Beban Jembatan}

Untuk beban jembatan terdiri dari struktur jembatan dan beban-beban yang bekerja di jembatan. digunakan data dari Jembatan Suramadu. Jembatan Suramadu adalah jembatan terpanjang di Indonesia saat ini. Pembebanan jembatan didasari oleh bagian struktur jembatan itu tersendiri. Pada area jembatan utama (main bridge), struktur yang digunakan adalah struktur kabel (cable stayed bridge), girder box, pylon, dan sebagainya. Jembatan Suramadu terdiri dari 4 lajur cepat dan 2 lajur darurat untuk kendaran roda empat serta 2 lajur sepeda motor (Departemen Pekerjaan Umum, 2007).

\section{METODE PENELITIAN}

\section{Pengumpulan data}

Pada kajian teknis kali ini data yang digunakan pada penelitian berasal dari data tanah sebuah proyek yang ada di Surabaya. Data yang dikumpulkan berdasarkan hasil dari uji lapangan dengan uji SPT (Standart Penetration Test)) dan hasil uji laboratorium.

\section{Pengolahan data}

Setelah data-data yang diperlukan sudah terkumpul, selanjutnya dilakukan pengolahan data. Pada tahap ini data diolah untuk mendapatkan berbagai parameter yang digunakan berdasarkan studi literatur yang sudah dilakukan sehingga dapat dilakukan analisis daya dukung pada fondasi tiang bor. Selanjutnya menghitung besar beban-beban yang mempengaruhi fondasi di laut. Setelah analisis daya dukung dan beban-beban dilakukan maka dilanjutkan dengan mereduksi daya dukung fondasi dengan beban-beban yang mempengatuhinya sehingga didapat daya dukung efektif fondasi, dan seberapa besar reduksi yang diterima oleh fondasi.

\section{Diagram alir penelitian}

Adapun diagram alir pada penelitian kali ini ditunjukkan pada gambar 3.

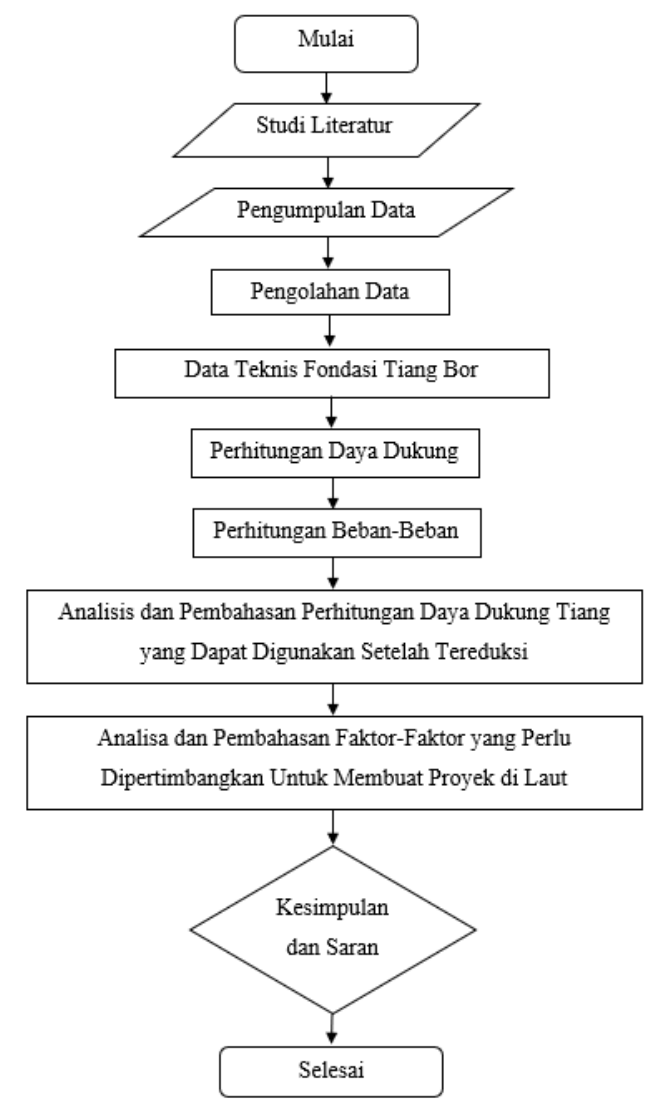

Gambar 3 . Diagram Alir Penelitian 


\section{HASIL DAN PEMBAHASAN}

Tiang yang digunakan pada penelitian ini adalah tiang bor dengan metode casing. Dengan data teknis fondasi yang dapat dilihat pada tabel 2.

Tabel 2. Data teknis fondasi

\begin{tabular}{lc}
\hline \multicolumn{1}{c}{ Parameter } & Data Teknis \\
\hline Tipe Fondasi & Bored Pile (Casing Method) \\
Kedalaman Laut & "- 19,0 m" \\
Panjang Fondasi & $78 \mathrm{~m}$ \\
Diameter Fondasi & $2,4 \mathrm{~m}$ \\
Diameter Casing Baja & $2,7 \mathrm{~m}$ \\
Panjang Casing Baja & $35,2 \mathrm{~m}$ \\
\hline
\end{tabular}

Pada penelitian ini tiang dipasang sampai kedalaman 78 meter. Dengan panjang casing baja 35,2 meter. Gambar fondasi tiang bor metode casing yang digunakan dapat dilihat pada gambar 4 .

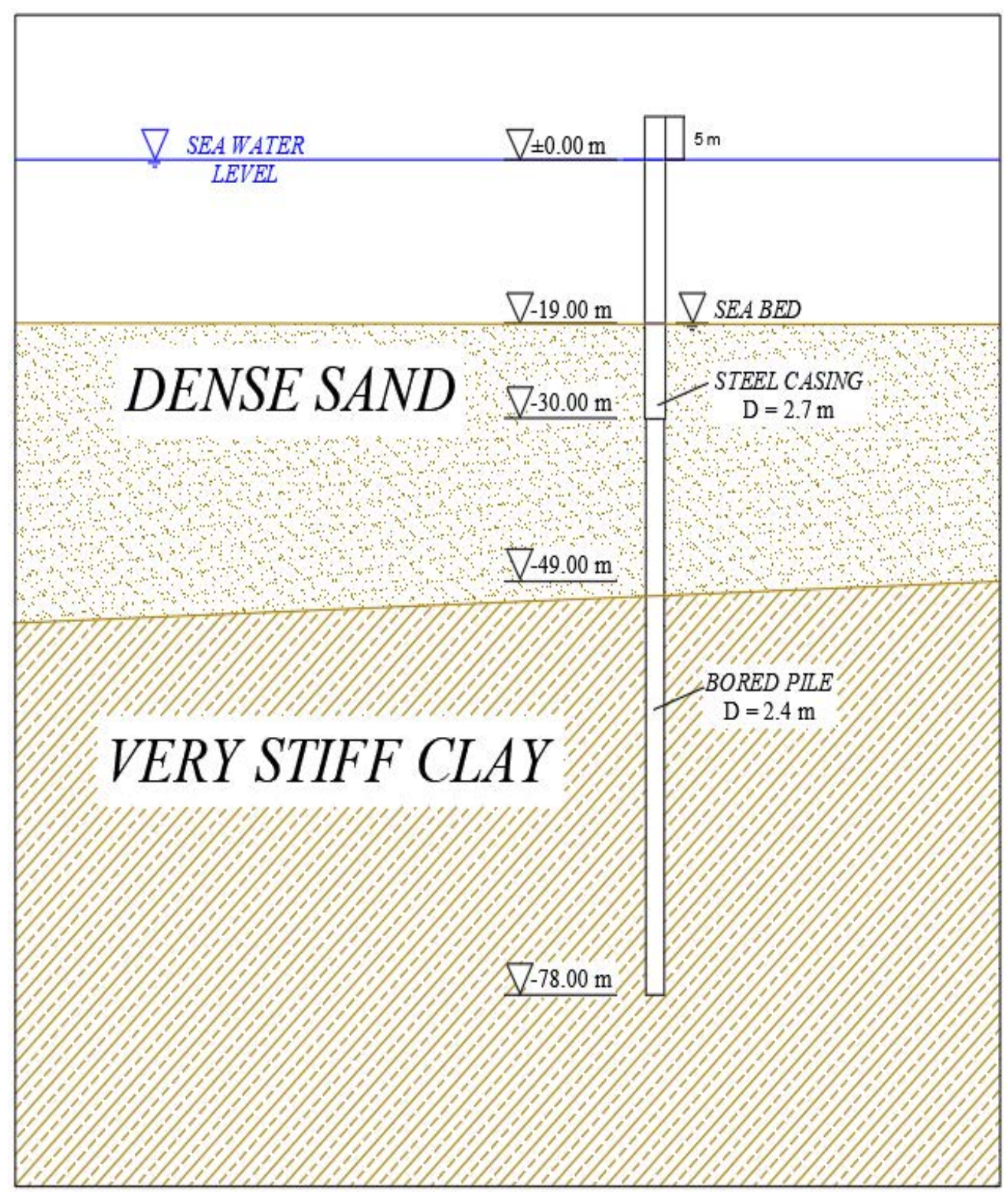

Gambar 4. Gambar fondasi tiang bor metode casing 


\section{Parameter tanah}

Untuk melakukan analisis daya dukung tiang diperlukan data parameter tanah. Penentuan parameter tanah dilakukan dengan melakukan korelasi berdasarkan data tanah dan mengacu pada tinjauan pustaka (Masyur, 2007). Summary parameter tanah yang digunakan dapat dilihat pada tabel 3.

Tabel 3. Summary parameter tanah

\begin{tabular}{cccccccc}
\hline $\begin{array}{c}\text { Kedalaman } \\
(\mathrm{m})\end{array}$ & Jenis Tanah & $\begin{array}{c}\mathrm{S}_{\mathrm{u}} \\
\left(\mathrm{kN} / \mathrm{m}^{2}\right)\end{array}$ & $\mathrm{c}\left(\mathrm{kN} / \mathrm{m}^{2}\right)$ & $\gamma\left(\mathrm{kN} / \mathrm{m}^{3}\right)$ & $\phi\left(^{\circ}\right)$ & $e$ & $\begin{array}{c}E_{\mathrm{s}} \\
\left(\mathrm{kN} / \mathrm{m}^{2}\right)\end{array}$ \\
\hline $0-5$ & Silty Sand & 260 & 520 & 19 & 29,5 & 0,4 & 35000 \\
$5-10$ & Sand & 245 & 490 & 19,5 & 29,5 & 0,45 & 44000 \\
$10-15$ & Silty Sand & 353 & 706 & 18,5 & 29,5 & 0,4 & 15000 \\
$15-20$ & Silty Sand & 170 & 340 & 15,9 & 29,5 & 0,4 & 15000 \\
$20-25$ & Gravelly Sand & 335 & 670 & 21,1 & 30 & 0,4 & 62500 \\
$25-30$ & Sand & 200 & 400 & 17 & 30 & 0,45 & 62500 \\
$30-35$ & Silt & 260 & 520 & 18,2 & 30 & 0,4 & 38000 \\
$35-40$ & Silty Clay & 149 & 298 & 16,2 & 30 & 0,6 & 38000 \\
$40-45$ & Silty Clay & 140 & 280 & 15,5 & 30 & 0,6 & 67000 \\
$45-50$ & Silty Clay & 175 & 350 & 16,7 & 30 & 0,6 & 67000 \\
$50-55$ & Silty Clay & 160 & 320 & 16,2 & 30 & 0,6 & 71000 \\
$55-60$ & Silty Clay & 200 & 400 & 17 & 30 & 0,6 & 71000 \\
$60-65$ & Silty Clay & 180 & 360 & 16,8 & 30 & 0,6 & 78500 \\
$65-70$ & Silty Clay & 245 & 490 & 17,8 & 30 & 0,6 & 78500 \\
$70-75$ & Silty Clay & 180 & 360 & 16,3 & 30 & 0,6 & 68000 \\
$75-80$ & Silty Clay & 150 & 300 & 16,4 & 30 & 0,6 & 68000 \\
$80-85$ & Silty Clay & 225 & 450 & 17 & 30 & 0,6 & 65000 \\
$85-90$ & Silty Clay & 280 & 560 & 18 & 30 & 0,6 & 65000 \\
\hline
\end{tabular}

\section{Perhitungan daya dukung tiang}

Berdasarkan parameter tanah tersebut dilakukan perhitungan daya dukung aksil dan daya dukung lateral tiang dari fondasi tiang bor metode casing. Summary daya dukung tiang dapat dilihat pada tabel 4.

Tabel 4. Summary daya dukung fondasi tiang bor metode casing

\begin{tabular}{lc}
\hline \multicolumn{1}{c}{ Parameter } & Tiang Bor Metode Casing \\
\hline Daya dukung ujung tiang & 1220 ton \\
Daya dukung selimut tiang & 4630 ton \\
Safety Factor & 4 \\
Daya dukung aksial tiang & 1460 ton \\
Daya dukung lateral tiang & 605 ton \\
\hline
\end{tabular}

\section{Perhitungan beban-beban}

Terdapat beban-beban yang mempengaruhi jembatan di laut. Untuk struktur di laut dengan bangunan bertingkat di darat terlihat bahwa beban vertikal tidak berbeda jauh, namun untuk beban lainnya jauh berbeda. Dalam penulisan ini yang termasuk dalam beban vertikal adalah beban jembatan yang harus diterima oleh fondasi sebesar 1700 ton dan beban coating untuk perlindungan korosi sebesar 5 ton. Sedangkan untuk beban lateral yang mempengaruhi lebih bervariasi, untuk summary beban-beban lateral dapat dilihat pada tabel 5 . 
Tabel 5. Summary perhitungan beban-beban lateral

\begin{tabular}{lccc}
\hline Beban Lateral & Nilai (ton) & Koefisien & Nilai Akhir (ton) \\
\hline Scouring & 10 & 1 & 10 \\
Tumbukan Kapal & 19 & 1,75 & 33,25 \\
Arus & 25 & 2 & 50,04 \\
Debris & 0,2 & & 93,65 \\
\hline
\end{tabular}

\section{Perhitungan daya dukung efeketif tiang}

Perhitungan untuk mencari daya dukung efektif tiang dapat dilakukan dengan mereduksi daya dukung tiang dengan beban-beban yang mempengaruhinya. Summary dari daya dukung efektif fondasi tiang dapat dilihat pada tabel 6 .

Tabel 6. Summary daya dukung efeketif fondasi

\begin{tabular}{lc}
\hline Parameter & Tiang Bor Metode Casing \\
\hline Daya dukung aksial & 1460 ton \\
Beban Coating & (5 ton) \\
Daya dukung aksial efektif & $\mathbf{1 4 5 5}$ ton \\
Gaya aksial maksimum & 1700 ton \\
Daya dukung lateral & 605 ton \\
Gaya lateral maksimum & $(112$ ton) \\
Daya dukung lateral efektif & $\mathbf{4 9 3}$ ton \\
\hline
\end{tabular}

\section{Hasil pembahasan}

Perhitungan persen reduksi dari daya dukung tiang akibat beban-beban yang mempengaruhinya

Persen reduksi daya dukung aksial $=\frac{1460-1455}{1460} \times 100 \%$

$$
=0,34 \%
$$

$\therefore$ Reduksi yang terjadi pada daya dukung aksial fondasi adalah 0,34 \%.

Persen reduksi daya dukung lateral $=\frac{605-493}{605} \times 100 \%$

$$
=18,5 \%
$$

$\because$ Reduksi yang terjadi pada daya dukung lateral fondasi adalah $18,5 \%$.

\section{KESIMPULAN DAN SARAN}

\section{Kesimpulan}

Berdasarkan hasil analisis dan pembahasan daya dukung tiang bor metode casing maka dapat disimpulkan bahwa:

1. Fondasi yang dapat digunakan untuk konstruksi di laut terdiri dari fondasi tiang pancang, fondasi tiang bor, fondasi caisson, cofferdam dan troll offshore platform.

2. Fondasi yang paling cocok untuk konstruksi di laut adalah fondasi tiang bor metode casing. Dikarenakan kedalaman laut yang dalam dapat menyebabkan pneumatic desease kepada para pekerja jika menggunakan fondasi pneumatic caisson. Kandungan air laut yang mengandung garam dapat menyebabkan korosi pada tulangan sehingga diperlukan casing untuk melindungi tiang bor.

3. Pelaksanaan konstuksi tiang bor di laut memiliki kendala dan risiko yang tinggi dibanding dengan pelaksanaan di darat. Sehingga diperlukan metode pelaksanaan konstruksi yang khusus seperti pembuatan platform sampai dengan pemilihan metode pengeboran. 
4. Untuk konstruksi di laut, beban lateral memberikan reduksi yang paling besar yaitu 18,5 \%. Sehingga beban lateral menjadi faktor penting jika ingin membuat struktur di laut.

5. Defleksi yang terjadi akibat beban lateral adalah 3,35 $\mathrm{mm}<$ Syarat defleksi maksimum tiang sebesar 6 mm. Sehingga fondasi kuat jika terkena beban-beban lateral yang ada.

6. Daya dukung aksial fondasi tiang bor metode casing lebih kecil dari pada gaya aksial maksimum yang diterima fondasi 1455 ton < 1700 ton. Sehingga untuk mendapatkan daya dukung aksial yang lebih besar dapat dilakukan penambahan panjang tiang bor atau menambah jumlah fondasi tiang bor dalam satu pile cap.

7. Pelaksanaan konstruksi fondasi tiang bor di laut dengan di darat memiliki beberapa faktor perbedaan. Faktor-faktor yang mempengaruhi fondasi di laut adalah beban-beban lateral yang lebih besar meliputi scouring, beban tumbukan kapal, beban arus, beban debris dan faktor buoyancy. Sedangkan untuk beban aksial terdapat beban coating yang berfungsi untuk perlindungan terhadapa korosi, sisanya tidak jauh berbeda dengan beban di darat meliputi beban struktur.

\section{Saran}

Dari hasil penelitian yang telah dilakukan, penulis memberikan beberapa saran untuk melengkapi kekurangankekurangan yang ada, antara lain:

1. Menggunakan software untuk menganalisa daya dukung fondasi sebagai pembanding dari hasil analisis yang telah dilakukan.

2. Perlu adanya data hasil uji laboratorium secara lengkap agar parameter tanah lebih spesifik dan hasil analisis menjadi lebih akurat.

3. Melakukan analisis untuk daya dukung kelompok fondasi pada satu pile cap.

4. Melakukan analisis beban gempa di daerah yang ditinjau sebagai beban lateral tambahan.

\section{DAFTAR PUSTAKA}

Almuhitsyah. Perencanaan Fondasi Jembatan Di Laut. Jakarta: Kementrian Pekerjaan Umum, 2012.

Bowles, Joseph E. Analisa dan Desain Pondasi Jilid 1. Trans. Pantur Silaban. 5th. Jakarta: Penerbit Erlangga, 1996.

Chomaedi. "Pelaksanaan Pondasi Bored Pile $\emptyset 240$ cm Main Bridge-Jembatan Suramadu." Fakutas Teknik Sipil Institut Teknologi Sepuluh Nopember (2009).

Das, Braja M. Mekanika Tanah (Prinsip - Prinsip Rekayasa Geoteknis) Jilid 2. Jakarta: Erlangga, 1995.

Departemen Pekerjaan Umum. Pelatihan Ahli Perencanaan Teknis Jembatan (Bridge Design Engineer). BDE-05 = Perencanaan Fondasi Jembatan. 2007.

Hardiyatmo, Hary Chirstiady. Teknik Pondasi 2. Yogyakarta: Gajah Mada University Press, 2008.

John, Ingargiola. Recommended Residential Construction for Coastal Areas. Building on Strong and Safe Foundations. FEMA P-550, 2019.

Masyur, I, et al. "Pengaruh Strength Reduction Tanah Clay-Shale Akibat Pelaksanaan Pemboran Terhadap Nilai Daya Dukung Pondasi Tiang di Jembatan Suramadu Berdasarkan Analisis Hasil Tes OC." Jurnal Teknik Sipil Vol.14 (2007).

Rindianto, Rahmatullah. "Desain Struktur Dermaga Curah Cair 15000 DWT pada Pelabuhan Pulang Pisau, Palangkaraya, Kalimantan Tengah dengan Meninjau Metode Pelaksanaan dan Estimasi Anggaran Biayanya." Institut Teknologi Sepuluh Nopember (2018). 